\title{
ACTIVE MANAGEMENT OF THIRD STAGE OF LABOUR, POST-PARTUM haEMorRhage AND maternal deATh RATE in the VANGa HeAlth Zone, Province of Bandundu, Democratic Republic of the Congo
}

Authors:

Jean-Pierre Fina Lubaki ${ }^{1}$

Jean-Robert Musiti Ngolo ${ }^{2}$

Lucie Zikudieka Maniati ${ }^{3}$

\section{Affiliations:}

${ }^{1}$ Vanga Hospital, Province of Bandundu, DR Congo

${ }^{2}$ Central Office of Vanga Health Zone, Province of Bandundu, DR Congo

${ }^{3}$ Maternal Child Health Integrated Program,

Kinshasa, DR Congo

Correspondence to: Jean-Pierre Fina Lubaki

email:

jeanpierrefina@yahoo.fr

\section{Postal address:}

Vanga Hospital, Province

of Bandundu, B.P. 4728

Kinshasa II, Democratic

Republic of Congo

Keywords:

active management of third stage of labour;

Democratic Republic of the Congo; maternal death post-partum haemorrhage rural health

Dates:

Received: 26 Apr. 2009

Accepted: 08 Sept. 2009

Published: 15 July 2010

How to cite this article: Fina Lubaki J-P, Musiti Ngolo J-R, Zikudieka Maniati L. Active management of third stage of labour, post-partum haemorrhage and maternal death rate in the Vanga Health Zone, Province of Bandundu, Democratic Republic of the Congo. Afr J Prm Health Care Fam Med. 2010;2(1), Art. \#76, 3 pages. DOI: 10.4102 / phcfm.v2i1.76

\section{This article is available} at: http://www.phcfm.org

(c) 2010. The Authors. Licensee: OpenJournals Publishing. This work

is licensed under the

Creative Commons

Attribution License.

\section{ABSTRACT}

Background: Post-partum haemorrhage (PPH) is the single largest cause of maternal death worldwide and a particular burden for developing countries. In Africa, about $33.9 \%$ of maternal deaths are due to PPH. In the Democratic Republic of the Congo (DRC), the prevalence of PPH is unknown. PPH can be prevented with active management of the third stage of labour (AMTSL).

Objectives: To describe the practice of AMTSL in Vanga Health Zone and to calculate the incidence of PPH in Vanga Health Zone.

Method: An intervention study with post-test-only design was conducted among health maternity wards using a data collection sheet to obtain information. All pregnant women attending Vanga Health maternity wards constituted the study population. Frequencies were determined for variables of interest.

Results: From April 2007 to March 2008, 6339 deliveries took place at Vanga Health maternity wards, representing $71 \%$ of the institutional delivery rate. The number of deliveries realised with the practice of (AMTSL) were 5562; 366 cases of PPH were reported, making an incidence of $5.77 \%$. Three cases of maternal deaths - two of which were related to PPH - were reported during the study period, which means there was a decline of $70 \%$ compared with the previous two years.

Conclusion: The prevalence of PPH has been estimated to be 5.77\%; PPH represents the cause of $67 \%$ of all maternal deaths. The extension of AMTSL practice, combined with the assurance of better supplies of oxytocin to enhance drug management, is strongly advised/suggested. As a number of births still take place outside the health maternity wards, the introduction of oral misoprostol could be considered a part of AMTSL for use by patients being treated by traditional midwives.

\section{INTRODUCTION}

Post-partum haemorrhage ( $\mathrm{PPH})$ is the single largest cause of maternal death worldwide, being a particular burden for developing countries. ${ }^{1,2,3}$ In Africa, about $33.9 \%$ of maternal deaths are due to PPH. ${ }^{3}$ In the Democratic Republic of the Congo (DRC) the prevalence of PPH is unknown, but it is estimated that PPH accounts for about $16 \%$ of maternal mortalities. ${ }^{3}$ In the Vanga Health Zone, one of the 515 health zones in the DRC, the maternal mortality rate has been calculated to 152/100 000 live births in 2006 and 2007; the prevalence of PPH is unknown. ${ }^{4,5}$

The most common definition of immediate PPH is blood loss of $500 \mathrm{~mL}$ or more in the first 24 hours following childbirth; severe PPH is defined as blood loss of $1000 \mathrm{~mL}$ or more. ${ }^{6}$ This definition is difficult to apply because some women, especially those who are anaemic, can develop hemodynamic disturbance with lower blood loss. In addition, an accurate estimation of the amount of blood loss during labour is difficult because in many rural settings only a visual assessment by the midwife is possible.

Every year, 14 million women experience PPH, and at least 128000 of these women bleed to death. ${ }^{7}$ Uterine atony causes $60 \%$ of $\mathrm{PPH} .{ }^{8}$ Two-thirds of $\mathrm{PPH}$ cases occur in women with no known risk factors. ${ }^{9}$

PPH can be prevented with AMTSL ${ }_{r}^{10}$ which is the administration of a uterotonic within the first minute of birth, controlled cord traction and uterine massage. ${ }^{11}$ Oxytocin is the drug of choice considering its effectiveness, cost, side effects profile, interval for therapeutic effect and storage. ${ }^{12}$ A large WHO multicentre randomised controlled trial (RCT) found that oxytocin, in hospital settings, is the drug of choice. $^{13}$

Four large-scale, randomised controlled trials that had compared active and expectant management of the third stage of labour found that AMTSL resulted in up to a 70\% decrease in PPH and a decrease in the duration of the third stage. ${ }^{14,15,16,17}$ The 2003 Cochrane Review found that AMTSL was associated with an approximate $60 \%$ reduction in the occurrence of $\mathrm{PPH}$ and severe $\mathrm{PPH}$, a decreased need for blood transfusion, a decreased post-partum anaemia $(\mathrm{Hgb}<9 \mathrm{~g} / \mathrm{dl})$, and an approximate $80 \%$ reduction in the use of therapeutic drugs. ${ }^{18}$

Based on the available evidence, the International Federation of Obstetricians and Gynecologists, and the International Confederation of Midwives, have agreed that the AMTSL should be offered to all women. ${ }^{11}$ Thadeus and Nangalia, in a study of the barriers to treatment of PPH, found that efforts to reduce the incidence of PPH as a major cause of maternal death must progress on two fronts: on the supply side, to ensure the provision of skilled care, and on the demand side, to ensure that women and their families accept the view that bleeding after birth is dangerous and that skilled care is preferable to traditional care. ${ }^{19}$

PPH is not listed as one of the indicators in the national system of health information in the DRC, which reflects that its importance is not recognised. After the conference on PPH in Entebbe, Uganda ${ }^{20}$ the 
Vanga Health Zone, with the use of oxytocin as uterotonic, was the first in the DRC to implement AMTSL to prevent PPH in its health centres at the first trimester of 2007. The implementation of AMTSL leads to a system of monitoring PPH in Vanga Health Zone. A study was designed in order to describe the practice of AMTSL and to calculate the incidence of PPH in the setting.

\section{ETHICAL CONSIDERATIONS}

The Health Ministry of the DRC has adopted the practice of AMTSL in 2008, and revised its directives for reproductive health. The study was conducted with the permission of the Vanga Health Zone authorities.

\section{METHOD}

\section{Study design}

The study was an intervention study with a post-test-only design among registered maternity centres of the Vanga Health Zone, in the Province of Bandundu, DRC. ${ }^{21}$

\section{Study setting}

The Vanga Health Zone is one of the 515 health zones in the Democratic Republic of the Congo. It is situated in the Province of Bandundu in the District of Kwilu. It covers an area of 2600 squared kilometres, with a population of about 222612 habitants. Vanga is rural in its entire area with agriculture being the main source of revenue. The population is poor and many families are not able to pay hospital bills, even for a normal delivery. It is estimated that the average daily income is about $\$ 0.50$.

The Vanga Health Zone has a general hospital and 48 peripheral health maternity wards. The furthermost health maternity ward of the Vanga Health Zone is about 90 kilometres from the hospital. Seven maternity wards have installed systems that provide electricity but only one of them (in the general hospital) seems to be reliable. The other systems were not functioning at the time of study. Routes of communication are in a disastrous state. The health centres are managed by nurses and deliveries are supervised by trained midwives.

The Vanga Health Zone has an average institutional delivery rate of about $77 \%$ and the maternal mortality has been calculated to $152 / 100000$ births in 2006 and 2007.,5

\section{Study population}

All pregnant women who attended the Vanga Health Zone maternity wards represented the study population. Approximately 6339 pregnant women took part.

\section{Data collection}

A one-week training session on $\mathrm{PPH}$ was organised for all midwives working in the 48 health maternity wards.

A data collection sheet, with all the information necessary to assess the variables of the study, was designed and copies were sent to all maternity wards to be filled out monthly by the midwives. Once the sheets were completed they were sent to the Central Office of the Vanga Health Zone so that the data could be entered into a computer. To enhance the validity of the information, a supervised data-quality audit was performed during the study period. The duration of the study was one year, from 01 April 2007 to 30 March 2008.
Each month, 40 sheets were received from the health centres and hospital maternities. ${ }^{5}$

\section{Variables}

- Number of institutional deliveries.

- Number of institutional deliveries with AMTSL

- Number of cases PPH.

- Number of cases of maternal death

\section{Analysis}

Data gathered from the health maternity wards were entered in the computer. Frequencies have been calculated for key variables of interest.

\section{Bias}

Biases present in this study can be identified as: ${ }^{22}$

- Observer bias, due to the fact that the definition of PPH is largely subjective. The training of midwives could be a way of minimising this bias.

- Selection bias, due to the fact that not all women were delivering in health maternity wards. The researchers supposed that the Vanga Health Zone had a high institutional delivery rate and that the segment of the pregnant women attending the health maternity wards could therefore be regarded as being a representative example of the characteristics of the wider population of interest.

\section{RESULTS}

The study took place from 01 April 2007 to 30 March 2008. During this period, 576 data collection sheets were received during the study period from the 48 health maternities. Of these, 531 data collection sheets came from health centres, representing a proportion of $92 \%$. Table 1 summarises the information gathered from the data collection sheets.

\section{Institutional deliveries}

With a total population of 222612 inhabitants, it was estimated that 8904 deliveries were expected during the study period in the Vanga Health Zone. There were 6339 deliveries registered in the 48 maternities, representing an institutional delivery rate of $71 \%$. Of these deliveries, 293 were caesarean sections, constituting $4.66 \%$ of institutional deliveries.

\section{Active management of third stage of labour}

AMTSL was practiced in 5562 of the deliveries, representing a proportion of $88 \%$ of the total 6339 deliveries that took place in the maternities.

\section{Post-partum haemorrhage}

Three hundred and sixty-six cases of PPH were reported from the maternities, constituting a proportion of $5.77 \%$ of all the deliveries. Three hundred and sixty-four cases of PPH were resolved after treatment; two cases resulted in death. Six cases of $\mathrm{PPH}$ were referred by the health centres to the general hospital, representing a proportion of $1.6 \%$.

\section{Maternal death}

Three maternal deaths were reported during the study period in the Vanga Health Zone, two of which were due to PPH. One of the six cases of PPH that was referred by health centres to

TABLE 1

Distribution of deliveries in Vanga Health zone

\begin{tabular}{|c|c|c|c|c|c|}
\hline \multirow[t]{3}{*}{ Setting } & \multicolumn{3}{|c|}{ Quantity } & \multirow{2}{*}{\multicolumn{2}{|c|}{$\begin{array}{c}\text { Outcome } \\
\text { Cases of PPH }\end{array}$}} \\
\hline & \multirow[t]{2}{*}{ Institutional deliveries } & \multirow{2}{*}{$\begin{array}{l}\text { Institutional deliveries } \\
\text { with AMSTL }\end{array}$} & \multirow[t]{2}{*}{ Cases of PPH } & & \\
\hline & & & & Stop & Death \\
\hline Vanga health Zone & 6339 & 5562 & 366 & 364 & 2 \\
\hline
\end{tabular}


the general hospital subsequently died of severe anaemia. Compared with the two previous years, in which 10 cases of maternal deaths were reported annually, the results noted a decrease of $70 \%$ in maternal deaths.

\section{DISCUSSION}

The Vanga Health Zone is one of the older pilot health zones of the DRC, where the participation of the population in sustaining health structures is one of the best in the country. It has a high institutional delivery rate of $71 \%$ compared with national average of $42 \%$. This institutional delivery rate is similar to what was found in a study in a rural district of Zimbabwe (75\%) but higher compared to that found in rural Nigeria $(51 \%) .{ }^{23,24}$ In Vanga, the caesarean section rate was $4.66 \%$, while it was estimated to $6.3 \%$ in the previous cited study in Zimbabwe and $9.1 \%$ in a study in Ghana, Nigeria. ${ }^{23,25}$ Indications for the caesarean sections have not been assessed in our study. Misoprostol has been recommended for use in settings where the necessary supplies are not available to give an injection of oxytocin. ${ }^{26}$ In our context, even if the majority of health centres have no electricity, it is assumed that oxytocin can be administered without major problems.

Many health centres, ranging from $5.5 \%-8.52 \%$ quarterly, ran out of oxytocin during the survey, ${ }^{27}$ so that the drug coverage of AMTSL was $88 \%$ of institutional deliveries. Extending the coverage of AMTSL in Vanga health zone could be achieved through better supply of oxytocin to health centres.

The identification of PPH by means of visual recognition of abnormally-excessive bleeding after birth is largely dependent upon the experience of practitioners. Therefore, the results of the study could have been influenced, and even compromised, by the under- or over-reporting by practitioners. Prendiville, Elbourne and McDonald found that clinical estimates of blood loss are generally thought to be underestimated by $35 \%-50 \% .{ }^{18}$ In clinical trials of oxytocin in AMTSL, the occurrence of PPH has been fewer than in this study, ${ }^{13,28}$ highlighting the gap that exists between research and reality.

Three maternal deaths were reported during the study. One may note that the pregnant women were surveyed only when attending the maternity for delivery and not during the pregnancy, which represented a limitation in assessing the maternal mortality rate. Nevertheless, a dramatic decrease of maternal deaths was noted.

\section{ACKNOWLEDGEMENTS}

The authors thank the ACCESS program for the technical support during the implementation of AMTSL in Vanga. The ACCESS program is the U.S. Agency for International Developmentss global program to improve maternal and newborn health. It works to expand the coverage, access and use of key maternal and newborn health services across a continuum of care from the household to the hospital, with the aim of making quality health services accessible as close to the home as possible. Jhpiego implements the program in partnership with Save the Children, Constella Futures, the Academy for Educational Development, the American College of Nurse-Midwives and IMA World Health.

\section{Funding information}

This publication was in part made possible through support provided by the Maternal and Child Health Division, Office of Health, Infectious Diseases and Nutrition, Bureau for Global Health, U.S. Agency for International Development, under the terms of the Leader with Associates Cooperative Agreement GHS-A-00-04-00002-00. The opinions expressed herein are those of the editors and do not necessarily reflect the views of the U.S. Agency for International Development.

\section{REFERENCES}

1. AbouZahr C. Global burden of maternal death and disability. British Medical Bulletin. 2003;67:1-11.
2. World Health Organization. Maternal Mortality: A Global Factbook. Geneva: WHO; 1991.

3. Khan KS, Wojdyla D, Say L, Gülmezoglu AM, Van Look PFA. WHO analysis of causes of maternal death: A systematic review. Lancet. 2006;367:1066-1074.

4. Zone de santé rurale de Vanga. Rapport annuel 2006. Vanga: ZSV; 2007.

5. Zone de santé rurale de Vanga. Rapport annuel 2007. Vanga: ZSV; 2008.

6. Prendiville WJ, Elbourne D. Care during the third stage of labor. In: Chalmers I, Enkin M, Keirse MJNC, editors. Effective Care in Pregnancy and Childbirth. Oxford: Oxford University Press, 1998; p. 1145-1169.

7. World Health Organization (WHO). Mother-Baby Package: Implementing Safe Motherhood in Countries. Geneva: WHO; 1998.

8. AbouZahr. Antepartum and post-partum haemorrhage. In: Murray CJL, Lopez AD, editors. Health dimensions of sex and reproduction: The global burden of sexually transmitted diseases, maternal conditions, perinatal disorders, and congenital anomalies. Geneva: WHO, 1998; p. 165-190.

9. Akins S. Postpartum haemorrhage. A 90s approach to an age-old problem. J Nurse Midwifery. 1994;39:123S-134S.

10. McCormick M, Sanghvi H, Kinzie B, McIntosh N. Preventing postpartum hemorrhage in low-resource settings. Int $\mathrm{J}$ Gynaecol Obstet. 2002;77:267-275.

11. FIGO ICM Joint Statement. Management of third stage of labour to prevent post-partum Haemorrhage. 2003.

12. WHO recommendations for the prevention of postpartum haemorrhage. Geneva: WHO; 2007.

13. Gülmezoglu AM et al. WHO multicentre randomised trial of misoprostol in the management of the third stage of labour. Lancet. 2001;358:689-695.

14. Bagley C. A comparison of active and expectant management of the third stage of labour. Midwifery. 1990;6:3-27.

15. Khan GQ. Controlled cord traction versus minimal interventions techniques in delivery of the placenta: A randomized controlled trial. Am J Obstet Gynecol. 1997;177:770-774.

16. Prendiville WJ, Elbourne D, Chalmers I. The effects of routine oxytocic administration in the management of third stage of labour: An overview of the evidence from controlled trials. Br J Obstet Gynaec. 1998;95:3-16.

17. Rogers J, Wood J, McCandlish et al. Active versus expectant management of third stage of labour: The Hinchingbrooke randomised controlled trial. Lancet. 1998;351:693-699.

18. Prendiville W, Elbourne D, McDonald S. 2003. Active versus expectant management of the third stage of labour. [Cochrane Review] In: The Cochrane Library, Issue 3, 2003. Chichester, Update Software.

19. Thaddeus S, Nangalia R. Perceptions Matter: Barriers to treatment of post-partum haemorrhage. J Midwifery Womens Health. 2004:49(4):293-297.

20. Sanghvi H, Lewison D, editors. Report of a conference in Entebbe. Preventing Mortality from post partum hemorrhage in Africa: Moving from Research to Practice; 2006 April 4-7; Entebbe, Uganda. JHPIEGO, Baltimore; 2006.

21. Leedy P. Practical research: planning and design. Columbus: Merrill; 1997.

22. Bowling A. Research methods in health: Investigating health and health services. Oxford: Oxford University Press; 2002.

23. Nilses C, Nyström L, Munjanja S, Lindmark G. Self-reported reproductive outcome and implications in relation to use of care in women in rural Zimbabwe. Acta Obstet Gynecol Scand. 2002;81(6):508-515.

24. Nwakoby BN. Use of obstetric services in rural Nigeria. J R Soc Health. 1994;114(3):132-136.

25. Martey JO, Djan JO, Twum S, Browne EN, Opoku SA. Maternal mortality due to post-partum haemorrhage. Int J Gynaecol Obstet. 1993;42(3):237-241.

26. Goldberg AB, Greenberg MA, Darney PD. Misoprostol and pregnancy. N Engl J Med. 2001;344:38-47.

27. Vanga Post-Partum haemorrhage Project. Monitoring and evaluation report. Vanga: VPPHP; 2008.

28. Oboro V, Tabowei TO. A randomised controlled trial of misoprostol versus oxytocin in the active management of the third stage of labour. J Obstet Gynaecol. 2003 Jan;23(1):13-16. 